\title{
A estética na sociedade globalizada e tecnológica*
}

\author{
Esthetics in technological \\ and globalized society
}

\section{La estética en la economía globalizada y tecnológica}

\author{
CHRISTINA MARIA \\ PEDRAZZA SEGA
}

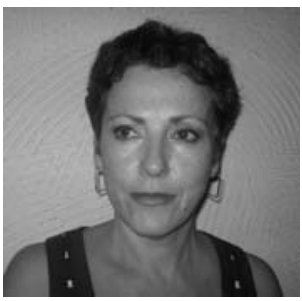

Docente na Faculdade de Comunicação da Universidade de Brasília. Integra o Programa de Pós-graduação da FAC/UnB, na linha de pesquisa em Teorias e Tecnologias da Comunicação. Doutora em Ciências da Comunicação pela Universidade Nova de Lisboa (Portugal), na área de concentração de Comunicação e Ciências Sociais. Mestre em Letras, na área de concentração em Lingüística Aplicada, pela Puccamp. Bacharelado em Publicidade e Propaganda pela Puccamp e licenciada em Letras pela Unesp.Emails: segach@unb.br; segach@hotmail.com.

* Texto apresentado no Intercom 2006, no Núcleo de Publicidade e Propaganda (NPP). 


\section{Resumo}

O fenômeno da globalização teve origem no mercantilismo durante a Idade Média. Todavia, a palavra "globalização" espalhou-se na economia mundial nas últimas décadas do século XX. Com o mercado globalizado e tecnológico, certos produtos tiveram sua estética alterada para agradar a economia mundial. Palavras-chave: Globalização - Estética - Publicidade - Tecnológico.

\section{Abstract}

The phaenomenon of globalization had its origin in the Mercantilism during the Middle Age. Nevertheless, the word "globalization" spread in the world economy in the last decades of the 20th century. With the globalized and technological market, certain products had their esthetic altered to please the world economy.

Keywords: Globalization - Esthetics - Advertising - Technological.

\section{Resumen}

El fenômeno de la globalización tuvo su origen en el Mercantilismo durante la Edad Media. La palabra "globalización" se esparció en la economía mundial en las últimas décadas del siglo XX. Con el mercado globalizado y tecnológico, algunos productos tuvieron su estética alterada para agradar la economía mundial y se tornaron "kitsch".

Palabras claves: Globalización - Estética - Publicidad - Tecnológico. 

través de uma pretensão democrática a favor da liberdade econômica, a globalização veio se expandindo nos mercados internacionais, direcionando a produção políticoeconômica e tecnológica rumo a soluções certas para o final do século XX e para o decorrer do século XXI.

\section{Globalização: mundialismo ou mundialização?}

A pesar de a expressão "globalização" ter surgido nas últimas décadas do século XX, a origem do processo da globalização remete à expansão do comércio mercantilista na Idade Média. Todavia, foi durante os séculos XVII e XIX que a globalização veio alcançando mais consistência em certos setores da economia mundial, avalia Thompson (1998). A palavra "globalização" vem adquirindo outros sinônimos, acrescenta esse autor, como "internacionalização" e "transnacionalização". A globalização se realiza toda vez que certas atividades ocorrem globalmente, de forma planejada e organizada, e quando tais atividades estabelecem um grau de reciprocidade e interdependência entre diferentes partes do mundo.

Seguindo a ampla nomenclatura ligada com esse vocábulo aparece o termo "mundialismo" em contraposição ao termo “mundialização". Segundo Passet (2003), há uma distinção entre esses dois conceitos. $\mathrm{O}$ autor recorre aos dicionários franceses Larousse e Robert para diferenciá-los. Define "mundialização" como aquilo que é analisado pela observação dos fatos políticos e socioeconômicos que ocorrem no mundo. Já o "mundialismo" é uma "opção ideológica", uma visão de mundo fundamentada em valores socioculturais. Por outro lado, Pierre Warnier (2003, p. 91) descreve a globalização por meio da "mundialização da cultura", que aliás é título de sua obra sobre esse assunto, e faz uma crítica à diversidade das situações e às desigualdades mun- 
diais no que se refere à cultura industrial, massificando-se cada vez mais a estética e os produtos produzidos pela globalização da indústria cultural.

Essa massificação cultural e estética está presente na sociedade globalizada atingindo certos setores econômicos. Pode-se, então, notar a presença do kitsch ${ }^{1}$ como estética de massa resultante do processo da economia globalizada. Dessa forma, o kitsch também pode ser analisado fora do âmbito da arte. Ele é identificado através de algumas características como: imitação ou perda da autenticidade, deslocamento do espaco-tempo, exagero e perda da função original. A moda e a culinária, entre outros setores, são exemplos típicos dos efeitos de uma economia globalizada. Apenas os países industrializados da América do Norte, Europa e Ásia são os mais privilegiados quanto à produção e recepção de bens culturais, sendo que as camadas sociais mais elevadas são as únicas que usufruem dessa troca econômica e cultural. Nesse intercâmbio étnico-cultural vê-se que são feitas muitas "adequações” àquilo que vem de fora da cultura local. Quando ocorre alguma interferência nessa cultura pode haver uma manifestação do kitsch no momento dessa adequação.

Sabe-se que foi na metade do século XX que aconteceram as grandes transformações econômicas mundiais, constatou Warnier. A partir de 1950 as empresas multinacionais se desenvolveram e os países industrializados começaram a diminuir as barreiras alfandegárias e expandiram as trocas mundiais pelos acordos multilaterais. Na década de 1980, com a dissolução do Bloco de Leste e com a abertura da China, iniciaram-se as trocas entre os mercados econômicos em caráter planetário. "A globalização se efetua por uma globalização dos mercados inclusive no âmbito de bens culturais", enfatiza Warnier (2003, p. 65).

\section{O kitsch na cultura globalizada}

A indústria cultural, por sua vez, apropria-se da globalização e elabora uma cultura de massa vinda dos países ricos, distribuída

\footnotetext{
1 Kitsch: pseudo-arte; de gosto inferior. Cf. dicionário alemão Langenscheidts Taschen-Wörterbch, 1968. Também do verbo alemão verkitschen = falsificar, "vender gato por lebre" (expressão popular).
} 
em escala planetária por meio de uma mundialização cultural baseada na troca de mercadorias e produtos culturais como cinema, cd's, telenovelas, moda, culinária etc. Há, dessa forma, um "deslocamento do espaço geográfico e cultural", próprio da globalização, sinalizando a presença do kitsch.

Warnier (2003, p. 33-55) considera que o labirinto histórico da globalização é constituído por quatro linhas de percurso: a) a fragmentação cultural da humanidade; b) as trocas mercantis; c) os transportes e a comunicação; d) a industrialização. A partir da década de 1990 a globalização aliou-se a uma outra parceira que consideraríamos a quinta linha do percurso: as novas tecnologias da comunicação e da informação - a informática. E o kitsch pegou carona com essa companheira fantástica, rápida e eficiente.

Referindo-se à crítica das práticas mediatizadas pelas novas tecnologias de informação e comunicação, Ciro Marcondes (2002, p. 220-6) propõe que fosse debatida a "teoria do valor cultural" dos bens culturais mediáticos a fim de que esses bens não fiquem apenas submetidos aos critérios de mercado, apesar de os receptores desses bens já terem "um julgamento do nível estético, informativo ou mesmo técnico dos produtos", visto que os produtos e serviços oferecidos pela internet também fazem parte da chamada indústria cultural.

Até mesmo o termo "mídia" pode ser considerado kitsch. Ciro Marcondes critica categoricamente a escrita aportuguesada dessa palavra que vem do inglês "mass media" (cuja pronúncia é mídia), que, por sua vez, se origina do latim "medium" - plural: "media". Assim, deveríamos escrever as palavras derivadas de "media" com 'e' e não com 'i' e, portanto, "mediático" e "mediatizar". Justifica Ciro Marcondes que "nada mais natural, como língua neolatina, seguirmos nossa tradição lingüística, como fizeram inteligentemente os portugueses".

A estética globalizada vem alcançando grandes espaços culturais e econômicos. Ao falar sobre globalização e música "tecno", Lévy (1999, p. 143) esclarece que a música tecno é criada por efeitos de digitalização do som e "sua universalidade resulta da compatibilidade técnica e da facilidade de circulação dos sons no ciberespaço". A globalização musical é apoiada pela indústria cultural e pelos meios de comunicação de massa. Acrescenta Lévy que 
todos os tipos de música étnicas, religiosas, clássicas ou outras são sampleadas, arrancadas do seu contexto original, mixadas, transformadas (...) e que o gênero transglobal (...) integra músicas tribais ou litúrgicas a sons eletrônicos, ou mesmo "industriais" sobre ritmos flutuantes ou frenéticos visando provocar efeitos de transe.

A economia mundial, assegurando-se em blocos, faz com que cada comunidade econômica produza e distribua produtos para atingirem interesses específicos. À medida que aumentam a oferta e a procura, intensifica-se a produção cada vez mais formatada para um destino certo. Com a globalização há uma perda da identidade nacional dos produtos a serem exportados, resultado de um consenso comum de cada bloco econômico. Os países que os importam acabam também perdendo suas características particulares para adotar um produto pronto, feito para todos. O caráter democrático é enfatizado pelo pensamento de que "todos têm direito a tudo", cuja ideologia do interesse próprio é diluída nos ideais de democratizar a economia, a política, a cultura, enfim, o bem-estar de todos.

Dominique Quessada (2003, p. 39) menciona o pensamento do professor norte-americano Theodor Levitt, de Harvard, como criador do termo "globalização", compreendendo que

algumas heranças morrem gradualmente, outras prosperam e se estendem porque constituem as preferências do maior número. Os mercadores étnicos são um bom exemplo disso: a pizそa e o jaž estão em toda parte. São segmentos de mercado que existem sobre bases mundiais. Eles não contradizem a homogeneização global, mas sim a confirmam.

Produtos globalizados no mundo inteiro, como os das marcas Coca-Cola e Nike usam, na maioria das vezes, o mesmo slogan ${ }^{2}$ para diferentes culturas e etnias, passando sempre a mesma ideologia do "prazer e do sucesso". Dessa forma, os países que sofreram os efeitos da globalização acreditam que

2 Slogan: frase curta e de grande efeito e que, à força de ser repetida, consagra um produto ou serviço. Cf. Erbolato (1986).

90 - Comunicação e Sociedade 47 
a globalização (...) é um dos principais motores do crescimento (...). Permitindo maior divisão do trabalho e uma repartição mais eficiente da poupança, a globalização traduz-se por um aumento da produtividade e do nível de vida (...). A competição internacional eleva a qualidade da produção e aumenta sua eficácia. ${ }^{3}$

Considerando-se os produtos de bens de consumos duráveis, especificamente os produtos eletrônicos (embora não sejam tão duráveis como antes, justamente para atender aos seus fabricantes), muitos já vêm com dupla ou tripla função - modelos 3 em 1 - para facilitar a vida de quem compra, tanto no aspecto prático e, supostamente, funcional, como no aspecto econômico, barateando o preço dessa mercadoria, caso fosse adquirida separadamente por funções a desempenhar.

Mas o lado funcional fica a desejar, visto que, quando uma função específica do aparelho deixa de ser exercida, ela acaba afetando boa parte do funcionamento restante do produto. Exemplo típico é o rádio-despertador. Se algo interno se desajusta você fica sem rádio, sem relógio e sem despertador.

É bom lembrar que essa idéia do 3 em 1 teve seu apogeu na década de 1960 nos EUA. Simultaneamente o Brasil, embalado no american way of life, começou a fazer uso desse tipo de produtos. A televisão conquistou os lares brasileiros, divulgando, através da publicidade, um novo estilo de vida. Os objetivos da globalização já tinham sido, de certa forma, esboçados por Marshall Mcluhan (1977) ao definir os "mutantes da nova era oral e tribal em dimensões planetárias", prevendo a "aldeia global" resultante dos meios de comunicação de massa.

Aos poucos a palavra globalização veio assumindo a conotação de massificação. Tende -se a globalizar a cultura e seu código cultural. O próprio idioma inglês já foi globalizado há muito tempo. Globalizam-se a moda, as tendências de consumo, a arte e a estética. Vê-se hoje o tênis Nike fabricado na Indonésia e vendido tanto nos EUA como em outros países. Perdendo a característica de autenticidade e de origem, muitos produtos da globalização tornam-se kitsch.

3 Cf. Boletim do FMI, de 19/05/1996. 
Muitos produtos não oficialmente globalizados, mas que já estão prestes a se assumirem como tais, encontram-se nas feiras dos importados. No entanto, a globalização é capaz de popularizar um produto ou elitizá-lo, dependendo de como este vai atender aos interesses da oferta e da procura.

$\mathrm{Na}$ sociedade capitalista e globalizada o consumo é impulsionado pela importância que é dada à aparência na vida do consumidor burguês. Desde que a burguesia surgiu no mundo, os indivíduos dessa classe viram-se impelidos a imitar a aristocracia e depois, nos séculos XX e XXI, a classe média se vê a imitar a classe alta, compulsivamente, como tentativa de solucionar suas frustrações sociopsicológicas. Esse fato só faz aumentar o kitsch na sociedade de massa. O maior estudioso desse assunto foi Abraham Moles (1975).

Em Crítica da estética da mercadoria Haug (1997, p. 34) comenta que, nesse desespero de "ser o que não é", muitas mercadorias camuflam suas verdades, criando uma aparência para atenderem ao mercado consumidor. Ele cita o caso do conhaque que não foi envelhecido em barril de carvalho e, para manter a aparência marrom, própria de um bom conhaque, atendendo à exigência dos compradores, recebe o colorido marrom com o acréscimo de açúcar caramelado. Camuflar a verdade ao imitar a cor de um produto nobre é uma característica kitsch pela imitação do original.

A globalização estimula a concorrência entre os produtos que procuram ser conhecidos no mercado externo. Por um lado, isso é extremamente saudável, pois todos têm direito a um lugar ao sol, e para tanto precisam investir cada vez mais na qualidade dos produtos e serviços para atender às exigências do consumidor. Por outro, isso faz com que venham a usar estratégias de venda que causam ilusões ópticas nos consumidores. Um caso típico disso é o exemplo citado por Haug sobre o fundo falso nas embalagens, colocado estrategicamente para disputar a concorrência direta com um outro produto similar.

O truste Henkel de Khasana, com a marca Creme 21, começou a concorrer com a marca Nívea, de Beirsdorf. Foi assim: por um preço de 2,90 marcos ofereceram latas com $150 \mathrm{~cm}^{3}$, que pareciam consideravelmente maiores que as latas de $150 \mathrm{~cm}^{3} \mathrm{da}$ 
Nívea, ao preço de 2,60 marcos. O efeito foi alcançado por meio de um espaço vazio de aproximadamente $6 \mathrm{~mm}$ a $13 \mathrm{~mm}$ de altura na parte interna da lata, invisível por fora (Haug, 1997, p. 47).

A atual sociedade de consumo é cada vez mais a 'sociedade da aparência no ter e no ser'. Os mitos greco-romanos da beleza e da sedução sempre são ressuscitados pela cultura de massa, que se alia à globalização da cultura e da economia de produtos recheados de ideologias e cobertos por retóricas cada vez mais persuasivas, suscitando o desejo por necessidades supérfluas como se fossem imprescindíveis à sobrevivência humana. Isto faz com que lembremos o mito de Tântalo na sociedade de consumo, citado por Haug (1997, p. 47) ao referir-se à obra de Mattenklott (1970). Conta a história que, na mitologia romana, Tântalo roubou os manjares dos deuses para dá-los aos homens. Como castigo recebeu o desespero da sede, não alcançando a água, que sempre se afastava dele. Da mesma forma que Tântalo vivia sedento, os indivíduos na sociedade de consumo vivem sedentos de coisas que acreditam serem básicas, realmente necessárias.

\section{O kitsch na publicidade}

A publicidade fica ao lado da globalização, incentivando e divulgando a estética de consumo da massa. Como prova disso, os anúncios inseridos a seguir mostram a estética do gosto da maioria consumidora.

O primeiro anúncio - Shampoo Seda - coloca em destaque o "exagero" como uma das características da estética de massa, próprio do kitsch, cujo exagero pode ser encontrado nas formas, no espaço, na linguagem verbal e visual. Esse "exagero" vem se alinhando aos objetivos da globalização, fato que desperta a atenção, a curiosidade e a persuasão do consumidor na sociedade de massa e de consumo. Podemos observar isso no anúncio do Shampoo Seda, do fabricante Hair Innstitute Paris, onde o "exagero" é fortemente observado na linguagem visual (um cadeado com correntes amarrando e segurando os cabelos de uma mulher) de forma a sustentar a linguagem verbal na chamada do anúncio - "não deixe escapar a cor de seu cabelo" - e no interior do corpo do texto - “(...) prenda a cor de seu cabelo". A 
figura de linguagem utilizada na expressão "não deixe escapar a cor do seu cabelo" foi a prosopopéia - animização/personificação, pois 'escapar' é um comportamento animal e humano.

Os produtos anunciados do mesmo fabricante são shampoos, condicionadores e cremes para tratamento de cabelos tingidos. No interior do corpo do texto encontra-se a frase "prenda a cor de seu cabelo", expressão apoiada na linguagem visual, já comentada aqui. O produto anunciado é vendido no Mercosul e nos EUA e sua mensagem é compreendida em continentes diferentes, pois trata-se de um produto globalizado para uma economia e cultura globalizadas.

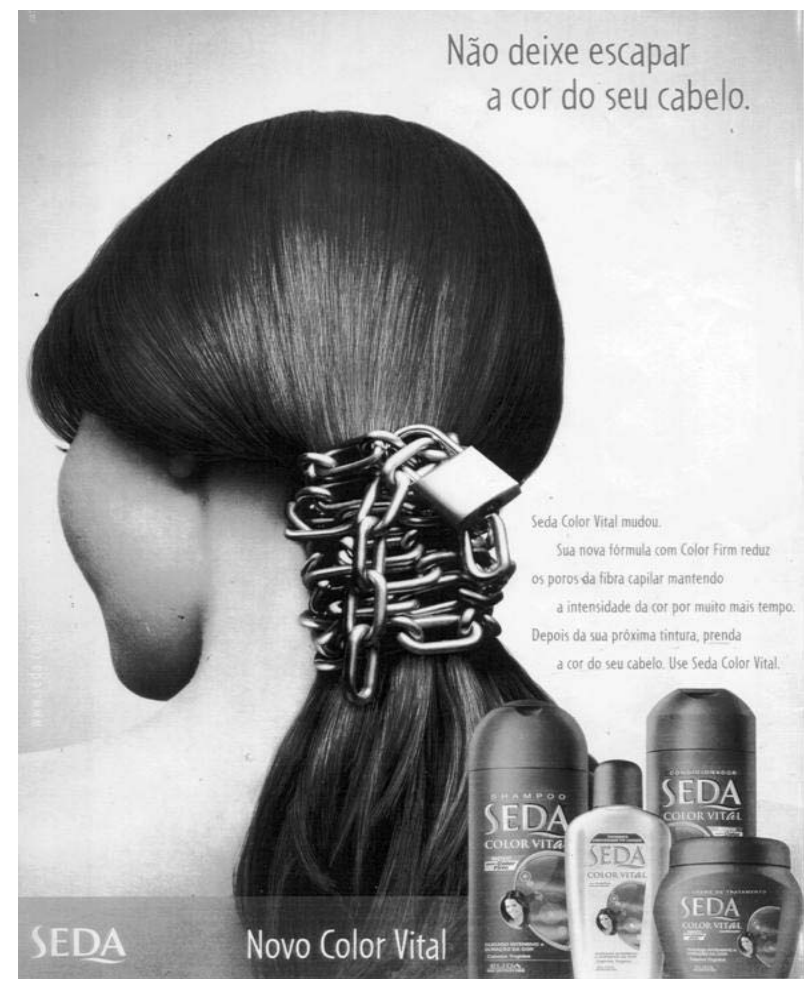

Shampoo e condicionador Seda Vital. Original em vermelho. Publicado nas revistas Marie Claire, Criativa, Contigo, Tititi 01/04/2004. 
O segundo anúncio que traz uma ideologia da estética globalizada é a do macarrão Nissin Lámen, versão light. A foto mostra a silhueta de uma mulher jovem, remetendo à silhueta de uma deusa grega ou romana, que ainda hoje é considerada um produto de beleza, em pleno século XXI, permanecendo o conceito de "mito da sedução" ao fazer a referência ao mito grego de Afrodite ou ao romano de Vênus. $\mathrm{Na}$ estética da globalização contemporânea vê-se na foto uma alusão ao passado longínquo das deusas do Olimpo, em pose de estátua grega e corpo nu.

O produto anunciado, um macarrão instantâneo versão light, oferece poucas calorias, proporcionando uma bela forma física aos seus usuários, em particular às mulheres, induzindo seu públicoalvo a comprá-lo, já que o produto é capaz de manter a elegância e as formas femininas. $\mathrm{Na}$ foto, um fio de macarrão é colocado na cintura de modelo venusiana ou afrodisíaca, sugerindo que tal produto contém 33\% menos de calorias e $85 \%$ menos de gordura, favorecendo a usuária desse produto na manutenção da silhueta desejada por qualquer mortal. O "deslocamento" do espaço determina, no anúncio em questão, uma outra característica kitsch da estética de massa. O macarrão Nissin Lámen foi deslocado dos lugares mais comuns de ser encontrado como na cozinha, na mesa ou até mesmo em direção à boca da modelo. Ao lado do "deslocamento" ocorreu simultaneamente uma outra característica kitsch, "a perda da função original”, pois o macarrão perdeu sua primeira função, de alimento, e adquiriu uma segunda função, a de adorno, portanto, um cinto. Assim, um fio de macarrão é colocado na cintura da modelo, em forma de cinto, sinalizando uma cintura fina, elegante e sedutora, concluindo que quem usar tal produto não perderá ou terá uma forma elegante e atraente.

Seguindo os passos da globalização, as sandálias Havaianas vêm alcançando uma trajetória de sucesso, ao longo desses quase trinta anos de publicidade da marca, por meio da elitização desse produto. Vale lembrar aqui que, para atender às exigências da globalização e da sociedade de massa, determinados produtos podem elitizar-se ou então popularizar-se, e isso vai depender dos objetivos de marketing e de comunicação das empresas. O produto começou sendo anunciado pelo humorista brasileiro Chico Anysio, 


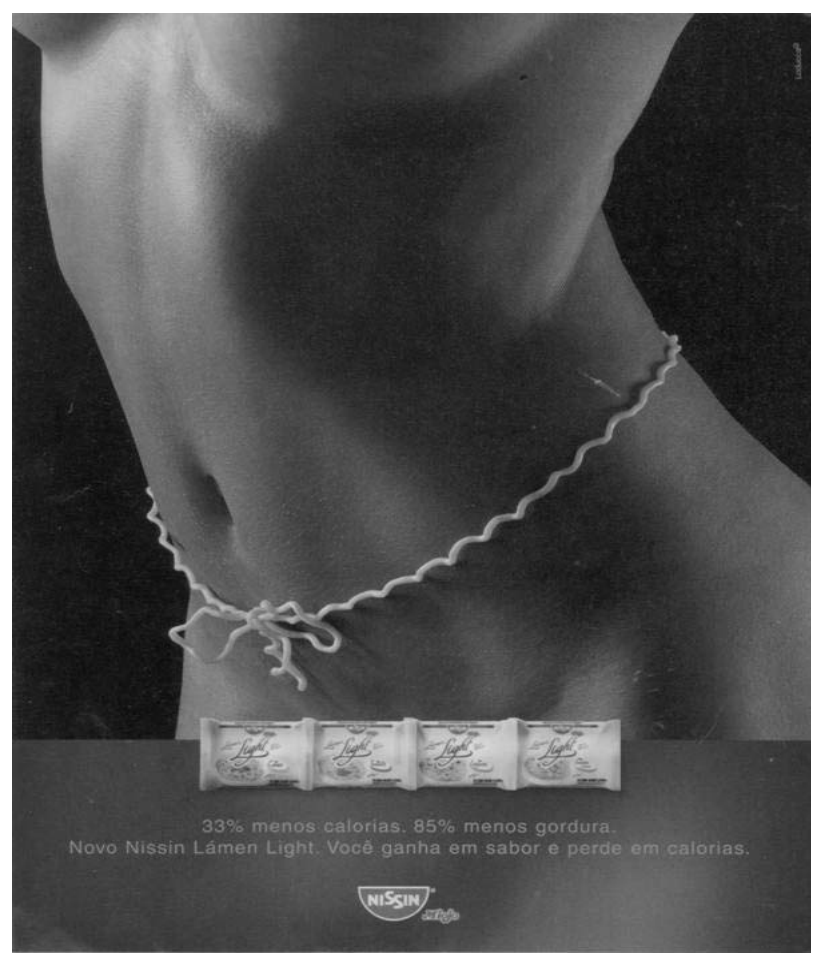

Macarrão Nissin Lámen Miojo

Publicado na revista Quem - 05/01/2004

tanto pela mídia eletrônica quanto pela impressa. Esse humorista, que conquistava massivamente os telespectadores, através de seus programas televisivos de grande audiência, sempre foi tido como um homem reconhecidamente inteligente por seu público e pela mídia. Foi o primeiro passo de elitização das Havaianas. Ficando um bom tempo com esse "garoto-propaganda", essa marca só tomou novo impulso quando se voltou ao público jovem, com novas opções de cores, combinando com as tendências da moda, usando em seus anúncios ídolos jovens de novelas, como Malu Mader acompanhada de um fã-clube masculino.

A grande fase de elitização foi com a musa da política nacional Tereza Collor, que, com sua elegância, sua simplicidade e seu carisma, conquistou mais adeptos da média burguesia. Finalmente, uma outra musa televisa da novela das oito, Carolina 
Ferraz, de beleza aristocrática e sobrenome tradicional, conseguiu manter o status do produto, que, apesar de ter nascido para a massa, nela se sofisticou adquirindo requinte pela leveza de sua linha e de sua opção de cores, além de ser um produto considerado barato. Em 2004, as Havaianas foram para as passarelas da moda na Europa. Seu preço lá fora chegou a quarenta euros na sua fase de lançamento.

Outros produtos sofreram influências das novas tecnologias e foram aceitos no mercado globalizado produzindo uma estética de massa.

\section{Referências biblioográficas}

ERBOLATO, Mário L. Dicionário de propaganda e jornalismo. 2. ed. Campinas: Papirus, 1986.

HAUG, Wolfgang Fritz. Crítica da estética da mercadoria. São Paulo: Unesp, 1997. LÉVY, Pierre. Cibercultura. São Paulo: Editora 34, 1999.

MACLUHAN, Marshall. A galáxia de Gutemberg. 2. ed. São Paulo: Companhia Editora Nacional, 1977.

MARCONDES, Ciro. Mediatismo ou o dilema do espetáculo de massas. In: PRADO, Aidar. Crítica das práticas mediáticas: da sociedade de massa à cibercultura. São Paulo: Hacker Editores, 2002.

MATTENKLOTT. Serviço das imagens: oposição estética em Beardsley e George. Munique/Alemanha: [s. n.]: 1970.

MOLES. Abraham. O kitsch. 2. ed. São Paulo: Perspectiva, 1975.

PASSET, René. Elogio da globalização. Rio de Janeiro, Record, 2003.

PRADO, J. L. Aidar. Crítica das práticas mediáticas: da sociedade de massa à cibercultura. São Paulo: Hacker Editores, 2002.

QUESSADA, Dominique. O poder da publicidade na sociedade consumida pelas marcas. São Paulo: Futura, 2003.

THOMPSON, John B. A midia e a modernidade. Petrópolis: Vozes, 1998.

WARNIER, Jean-Pierre. A mundialização da cultura. 2a. ed. Bauru: Edusc, 2003. 